\title{
THE PROTECTIVE ROLE OF COENZYME Q10 AGAINST NANDROLONE DECANOATE-INDUCED CARDIOTOXICITY IN RATS: BIOCHEMICAL, GENETIC, HISTOLOGICAL AND IMMUNOHISTOCHEMICAL STUDY.
}

\author{
Dalia Mohamed Alia ${ }^{a}$ Dina Ahmad Aly Labib2 ${ }^{\text {b }}$, Mai Mohamed Nabil Mohamed ${ }^{c}$ \\ ${ }^{a}$ Forensic Medicine \& Toxicology Department, Faculty of Medicine, Minia University, ${ }^{b}$ \\ Pharmacology Department, Faculty of Medicine-Cairo University, ${ }^{\mathrm{c}}$ Biochemistry \\ Department, Faculty of Medicine-Ain Shams University, Egypt
}

\begin{abstract}
Anabolic androgenic steroids (AAS) are still used broadly by athletes, even though they are barred in sports, to increase cardiac performance and muscle mass rapidly. This study aimed to test the protective role of coenzyme Q10 against AAS induced cardiotoxicity in adult albino rat models. Twenty-four Wistar albino rats were divided into equal four groups administered ND (nandrolone decanoate) weekly at $(20 \mathrm{mg} / \mathrm{kg}$ ) subcutaneously with and without coenzyme Q10 $(10 \mathrm{mg} / \mathrm{kg})$ orally every day for 4 weeks. The results revealed that ND induced a significant increase in the mitochondrial enzyme SDH (succinate dehydrogenase) and mitochondrial calcium level, alteration in the serum level of CK-MB (Creatine PhosphoKinase-MB), and enhancement of apoptosis and fibrosis in the cardiac tissue. Histopathological study of the heart was done. Treatment with Q10 could alleviate the toxic effects induced by ND.
\end{abstract}

Keywords: Nandrolone decanoate, coenzyme Q10, heart, fibrosis, apoptosis.

\section{INTRODUCTION}

Anabolic androgenic steroids (AAS) were synthesized to simulate testosterone hormone structurally and functionally (Salas-Ramirez et al., 2008). AAS are used in the treatment of different diseases for example renal insufficiency, growth disorders, osteoporosis, some blood disorders, and reproductive system dysfunction (Kochakian, 2012). Nandrolone decanoate (17 $\beta$-hydroxy-19-nor-4androsten-3-one) is a common commercial anabolic steroid. It has a similar effect to testosterone but without virilization (Llewellyn, 2011). Nowadays, it is commonly used by athletes, bodybuilders, and weightlifters to increase their physical performance and muscle mass (Rocha et al., 2007). Nevertheless, those persons take these compounds in excessive doses that resulting in many organ dysfunctions (Sretenovic et al., 2016).

Regardless of some therapeutic use of AASs, misuse of anabolic steroids has become a widespread health problem. Several studies have reported that high doses of AAS induce many pathological lesions in the heart. The most common hazards are hypertension, altered lipid profiles (Nikolic et al., 2015), arrhythmias (Vasilaki et al., 2016) and acute myocardial infarcts (Wysoczanski et al., 2008). They may alter the myocardial ventricular function through the androgen receptor pathway (Figueredo, 2011; Luijkx et al., 2013). Also, ventricular hypertrophy (Mark et al., 2005), fibrosis, cardiomyopathy (Ahlgrim and Guglin, 2009), and even 
sudden death (Montisci et al., 2012) have been recorded.

Several previous studies showed that high doses of AAS induce oxidative stress and alter the antioxidant enzymes (Chaves et al., 2006). Reactive oxygen species (ROS) are byproducts of aerobic cellular metabolism. Oxidative stress is induced by the discrepancy between the intracellular antioxidant levels and generation of ROS which leads to ischemia reperfusion (I/R) injury, apoptosis and neurodegenerative diseases (Cadenas and Davies, 2000). Cardiomyocytes are the major patrons of molecular oxygen and are simply liable to oxidative tissue injury induced by ROS. Mitochondria are the most important source for production of ROS in cardiac cells and the use of some xenobiotics can add more oxidative damage leading to cardiotoxicity (Suchalatha et al., 2007).

Antioxidant agents have been extensively used for the treatment of damages induced by oxidative stress (El-Sayed et al., 2016). Coenzyme Q10 (Q10) is a fat-soluble substance, which resembles a vitamin, present mainly in the mitochondria in all cells of the human body. It is an important element of the electron-transport chain (Duberley et al., 2014). Deficiency of Q10 leads to multiple diseases such as diabetes, Parkinson's disease, breast cancer, coronary artery disease, and hypertension (Niklowitz et al., 2007). Q10 is a potent antioxidant used therapeutically in the treatment of such diseases (Yeung et al., 2015) and, moreover, it is commonly used as a nutritional supplement.

In 1976, steroids had become one of the doping agents which are barred by the International Olympic Committee (Hausmann, 2005). As steroids must be taken under supervision of a medical doctor, a black market has become popular due to the widespread of body building. There are several fatal cases and deaths related to chronic AASs abuse, have been reported, depending on the dose, duration and patterns of use (Frati et al., 2015). Hence, this study tried to assess histopathological and toxicological findings induced by AASs in adult albino rat models after 4 weeks and evaluate the cardio-protective role of coenzyme Q10 against this toxicity.

\section{MATERIALS \& METHODS}

\section{Chemicals}

Nandrolone decanoate (ND) commercially, known as Nandurabolin - was obtained from Chemical industrial Development Co. for the Nile Company for Pharmaceuticals and chemical Industries, Egypt. Every vial contains $50 \mathrm{mg} / \mathrm{mL}$ of the active ingredient in oily solution. Coenzyme Q10, Ubiquinone was obtained from Sigma Aldrich (Saint Louis, MO, USA) (CAS number: 303-98-0).

\section{Animals}

Twenty-four Wistar albino rats, weighing 200-220 gm, were obtained from the National Research Center, Cairo, Egypt. Rats were housed, had free access to standard rat chow (ElNile Company, Egypt) and tap water and allowed for appropriate adaptation to the animal house conditions (45 \pm $5 \%$ humidity and 12 hours lighting cycle at $25 \pm 2{ }^{\circ} \mathrm{C}$ ). One week after acclimatization, the rats were aimlessly divided into identical 4 groups: Group I (control group): was given the standard diet and water $(10 \mathrm{~mL} / \mathrm{kg}$ by oral gavage). Group II (Q10 group): was given the standard diet with Q10 (10 $\mathrm{mg} / \mathrm{kg} / \mathrm{day}$ in $10 \mathrm{~mL}$ water by oral gavage) according to Chen et al., 
(2017). This dosage is comparable to the recommended therapeutic dose in adults (Hechtman, 2014). Groups III (ND group) was given the standard diet with ND at $20 \mathrm{mg} / \mathrm{kg} /$ week subcutaneous (1/30 of the LD50) according to Nikolic et al., (2015). Group IV (treated group): was given the standard diet with ND and Q10 at the same previous doses. The treatments were given for 4 weeks. The protocol of the experiment was accepted by the Ethics Committee of Cairo University.

At the end of the experiment, all animals were anesthetized with ether and sacrificed. Blood samples were suitably collected from each rat and centrifuged (centrifuge Jantezki, T30, Germany), at $5000 \mathrm{rpm}$ for 10 minutes for serum collection. Then sera were separated and kept at $-80^{\circ} \mathrm{c}$ until estimation of TGF $\beta 1$ and Creatine PhosphoKinase-MB (CPK-MB). The hearts were surgically removed for examination. The left ventricular cardiac tissues were kept in $10 \%$ formalin designed for histopathological examination. $1 \mathrm{~cm}^{3}$ cardiac tissue blocks were dissected, wrapped in aluminum foil and immediately stored at $-80^{\circ} \mathrm{C}$ until needed for analysis.

Isolation Of Heart Mitochondria Mitochondria of the cardiac tissue were seperated according to Takasawa et al., (1993). After homogenization of the heart tissue, centrifugation was done at $700 \times \mathrm{g}$ for $20 \mathrm{~min}$, and the supernatant centrifuged again at $9000 \times \mathrm{g}$ for $15 \mathrm{~min}$. Then, washing of the pellet with $10 \mathrm{mM}$ Tris- $\mathrm{HCl}(\mathrm{pH}$ 7.8) containing $0.25 \mathrm{M}$ sucrose and finally re-suspended in the same buffer. The isolated mitochondria were frozen for measurement of the activity of the mitochondrial enzyme succinate dehydrogenase (SDH) and for measurement of the mitochondrial $\mathrm{Ca}^{2+}$ concentration.

Measurement of $\mathrm{Ca}^{2+}$ And SDH In Heart Mitochondria And CK-MB In Serum

Enzymatic methods by spectrophotometer techniques (Model JENWAY 6105 UV / VIS) were used for measurement of $\mathrm{Ca}^{2+}$, succinate dehydrogenase (SDH) and Creatine PhosphoKinase-MB (CPK-MB) levels by kit supplied by France ELITECH GROUP.

Detection Of Bax, Bcl2, Pakt \& Pi3k Protein By Western Blot Technique

Western blot technique of cardiac tissue (usingV3 Western Workflow ${ }^{\mathrm{TM}}$ Complete System, Bio-Rad® Hercules, CA, USA) was performed according to Wassef et al., 2017. The protein was supplied by (Pierce, Rockford, IL, USA). Specific primary antibodies for bax, bcl2, pakt, pI3k and beta actin obtained from (Thermoscientific, Rockford, Illinois, USA). ChemiDocTM imaging system was used to analyze band intensity with Image LabTM software version 5.1 (Bio-Rad Laboratories Inc., Hercules, CA, USA). The results were shown as arbitrary units following normalization for expression of $\beta$-actin protein.

Quantitative Analysis of Gene Expression Of MMP2 \& MMP9 By Real Time Qrt-PCR

Isolation of total RNA from cardiac tissue homogenates was done by SV Total RNA Isolation System (Promega, Madison, WI, USA) according to manufacturer's guideline. The concentrations and purity of RNA were detected by an UV-spectrophotometer.

Complementary DNA (Cdna) Synthesis $1 \mu \mathrm{g}$ RNA was used for production of the cDNA by SuperScript III First-Strand Synthesis System along with the manufacturer's protocol 
(\#K1621, Fermentas, Waltham, MA, USA).

\section{Real-Time Quantitative PCR}

Analysis and amplification of realtime PCR were done as formerly described by Wassef et al., 2017 by an Applied Biosystem with software version 3.1 (StepOne $^{\mathrm{TM}}$, USA). The specific primer pairs for each gene were revealed in table (1) and they were analyzed by Gene Runner Software (Hasting Software, Inc., Hasting, NY). The reaction had SYBR Green Master Mix (Applied Biosystems). The v1.7 sequence detection software from PE Biosystems (Foster City, CA) was used for calculation of the data from realtime assays. Comparative $\mathrm{Ct}$ method was used to calculate relative expression of the examined gene mRNA. Whole values were normalized to the reference gene $\beta$ actin.

\section{Detection Of TGF B1by ELISA}

enzyme linked immunosorbent assay kits, obtained from $\mathrm{R} \& \mathrm{D}$ system USA, was used to determine TGF $\beta$ in serum according to manufacturers' guidelines.

Table (1): The primer sequence of the studied gene

\begin{tabular}{|c|c|}
\hline & Primer sequence \\
\hline SDH & $\begin{array}{c}\text { Forward primer :5'- TGGCTTTCACTTCTCTGTTGG -3 } \\
\text { Reverse primer 5'- ATCTCCAGTTGTCCTCTTCCA -3 }\end{array}$ \\
\hline MMP-2 & $\begin{array}{c}\text { Forward :5-GTGCTGAAGGACACCCTCAAGAAGA -3 } \\
\text { Reverse: 5- TTGCCGTCCTTCTCAAAGTTGTACG -3 }\end{array}$ \\
\hline MMP-9 & $\begin{array}{c}\text { Forward primer : 5'- ACGGCAAGGATGGTCTACTG -3 } \\
\text { Reverse primer 5'- AGTTGCCCCCAGTTACAGTG -3 }\end{array}$ \\
\hline Beta actin & $\begin{array}{c}\text { Forward primer : - GGTCGGTGTGAACGGATTTGG -3 } \\
\text { Reverse primer:5'- ATGTAGGCCATGAGGTCCACC-3 }\end{array}$ \\
\hline
\end{tabular}

\section{Histopathological Examination}

Heart tissue specimens were collected from all experimental groups, 48 hrs fixation in $10 \%$ buffered formalin, and kept in paraffin then were cut at $4 \mu \mathrm{m}$ and stained by routine stain hematoxylin and eosin and Masson's trichrome for detection of connective tissue. Images of tissue sections were captured with a digital camera attached to the Olympus BX51 microscope.

\section{Immunohistochemical Stain}

TUNEL assay (Apotag plus Peroxidase in Situ Apoptosis Detection Kit, Chemicon, Tamecula, CA, USA) was done as previously described by Fineschi et al., (2011). Mayer's hematoxylin was used to stain the sections, then dried, cover slipped and examined under Olympus microscope. The intensity of immunopositively expression was evaluated semi quantitatively according to the scale 0-4 as follows: $0=$ no immunoreactivity in scattered cells, $1=$ mild immunopositivity in scattered cells, $2=$ up to $1 / 3$ of cells showed immunopositivity, $3=$ up to $1 / 2$ of cells showed immunopositivity and $4=$ majority of cells showed strong immunopositivity.

\section{Statistical Methods}

The statistical package SPSS version 24 was used for coding and entering data. Data was expressed as mean \pm standard deviation for quantitative variables. Analysis of variance (ANOVA) was done for comparisons between groups, with multiple comparisons post hoc test (Chan, 2003) to detect which groups' means differed. $P$-values $<0.05$ were considered as statistically significant. 


\section{RESULTS}

Measurement of $\mathrm{Ca} 2+$ in heart mitochondria, SDH \& $\mathrm{CK}-\mathrm{MB}$ in serum

Table 2 showed a significant raise in the calcium level in the heart mitochondria of ND group in comparison to the control group. Meanwhile, the treated group with Q10 revealed a significant reduction in the elevated calcium level as compared to the ND group. A significant reduction in the mitochondrial enzyme SDH in ND group when compared to the control rats, while, the treated group recorded a significant raise in comparison to ND group. Serum cardiac marker CK-MB significantly increased in ND group in comparison to the control group; conversely, treatment with Q10 recorded a significant reduction as compared to ND group.

Table (2): One-way ANOVA statistical analysis of the effect of Nandrolone decanoate (ND), coenzyme Q10 and their combination on the $\mathrm{Ca} 2+$ ion level and mitochondrial enzyme SDH in the heart mitochondria, and serum cardiac marker CK-MB in the examined rats $(n=6)$.

\begin{tabular}{|l|l|l|l|}
\hline & $\mathbf{C a} 2+$ & SDH & CK-MB \\
\hline Group I & $3.50 \pm 0.85$ & $1.04 \pm 0.05$ & $121.07 \pm 7.15$ \\
\hline Group II & $4.70 \pm 0.75$ & $1.05 \pm 0.08$ & $124.37 \pm 8.88$ \\
\hline Group III & $6.46 \pm 1.14 * \#$ & $0.39 \pm 0.16 * \#$ & $335.6 \pm 12.35^{*} \#$ \\
\hline Group IV & $4.11 \pm 0.47 \$$ & $0.81 \pm 0.12 \# \$$ & $134.88 \pm 5.61 \$$ \\
\hline P value & $<0.001$ & $<0.001$ & $<0.001$ \\
\hline
\end{tabular}

Calcium (Ca2+): $\mathrm{mol} / \mathrm{mg}$ mitochondrial protein.

Succinate dehydrogenase (SDH): nmol of succinate oxidized $/ \mathrm{min} / \mathrm{mg}$ protein.

Creatine Phosphokinase-MB (CK-MB): IU/L, Values are expressed as mean \pm SD, *: statistically significant in comparison to the control group $(\mathbf{P}<0.05)$. \#: statistically significant in comparison to the group $Q 10(P<0.05)$. \$: statistically significant in comparison to the group ND $(\mathbf{P}<0.05)$.

Detection Of Bax, Bcl-2, P-Akt \& P-PI3K Protein By Western Blot Technique

Figure 1 showed analysis of Bax, Bcl-2, p-Akt and p-PI3K protein expressions by Western blot. The survival proteins Bcl-2, p-Akt, p-PI3K were found to be reduced, meanwhile, apoptosis protein Bax level increased significantly in the ND group in comparison to the control rats. Meanwhile, the treated group revealed a significant augmentation in the levels of survival proteins and a significant decrease in the apoptosis protein as compared to the ND group. (Table 3)
Quantitative Analysis of Gene Expression Of MMP-2 \& MMP-9 By Real Time Qrt-PCR

The gene expressions of MMP-2 and MMP-9 fibrosis proteins in the heart tissue were quantified by realtime qRT-PCR. The result showed that exposure to ND affected the gene expression of MMP-2 and MMP-9 fibrosis proteins. The gene expression levels were increased significantly in ND group compared with those in control rats. While, the gene expression levels were decreased significantly in the treated group as compared with those in ND group. (Table 4) 
Table (3): One-way ANOVA statistical analysis of the effect of Nandrolone decanoate (ND), coenzyme Q10 and their combination on cell survival proteins Bcl-2, p-Akt $\&$ p-PI3K and apoptosis protein Bax in the heart tissue by Western Blot in the examined rats $(n=6)$.

\begin{tabular}{|c|c|c|c|c|}
\hline & Bcl-2 & p-Akt & p-PI3K & Bax \\
\hline Group I & $1.00 \pm 0.00$ & $1.04 \pm 0.03$ & $1.06 \pm 0.03$ & $1.00 \pm 0.00$ \\
\hline Group II & $1.02 \pm 0.02$ & $1.02 \pm 0.03$ & $1.03 \pm 0.03$ & $1.01 \pm 0.02$ \\
\hline Group III & $0.24 \pm 0.12^{*} \#$ & $0.43 \pm 0.12 * \#$ & $0.45 \pm 0.06^{* \#}$ & $12.75 \pm 1.81 * \#$ \\
\hline Group IV & $0.77 \pm 0.11^{*} \# \$$ & $0.93 \pm 0.07 \$$ & $0.99 \pm 0.04 \$$ & $2.58 \pm 0.92 \$$ \\
\hline P value & $<0.001$ & $<0.001$ & $<0.001$ & $<0.001$ \\
\hline
\end{tabular}

Values are expressed as mean $\pm \mathrm{SD}, *$ : statistically significant in comparison to the control group $(P<0.05)$. \#: statistically significant in comparison to the group Q10

$(\mathrm{P}<0.05)$. \$: statistically significant in comparison to the group $\mathrm{ND}(\mathrm{P}<0.05)$.

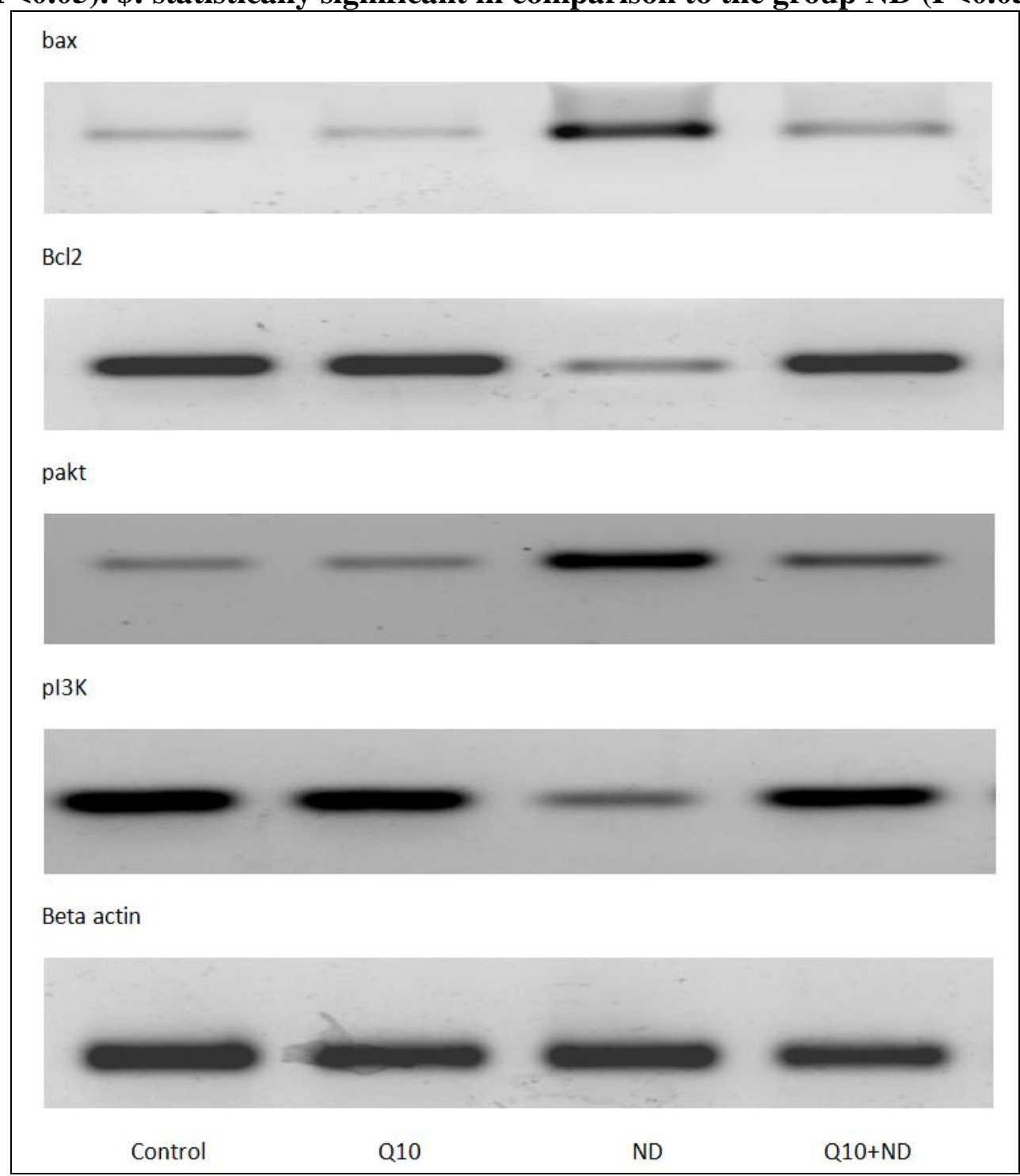

Figure (1): Effect of ND, Q10 and their combination on Levels of survival (antiapoptotic) protein $\mathrm{Bcl} 2$, pakt, $\mathrm{pI} 3 \mathrm{~K}$ and apoptosis protein Bax were determined by western blot. \{Lane1: Group I (control group), Lane 2: Group II (Q10 group), Lane 3: Group III (ND group), Lane 4: Group IV (Q10+ND group) \}. Quantitative statistics were done using one way ANOVA. 
Table (4): One-way ANOVA statistical analysis of the effect of Nandrolone decanoate (ND), coenzyme Q10 and their combination on the gene expression of MMP-2 and MMP-9 fibrosis protein in the heart tissue by PCR and serum TGF $\beta 1$ pro-fibrosis protein marker by ELISA in the examined rats $(n=6)$.

\begin{tabular}{|c|c|c|c|}
\hline & MMP-2 & MMP-9 & TGF $\beta 1$ \\
\hline Group I & $1.00 \pm 0.01$ & $1.04 \pm 0.06$ & $39.30 \pm 3.96$ \\
\hline Group II & $1.05 \pm 0.08$ & $1.02 \pm 0.03$ & $33.13 \pm 3.27$ \\
\hline Group III & $12.28 \pm 1.91 * \#$ & $15.75 \pm 2.01 * \#$ & $110.63 \pm 8.95 * \#$ \\
\hline Group IV & $5.21 \pm 1.07 * \# \$$ & $4.24 \pm 0.97^{*} \# \$$ & $70.62 \pm 6.58^{*} \# \$$ \\
\hline P value & $<0.001$ & $<0.001$ & $<0.001$ \\
\hline \multicolumn{4}{|c|}{ Values are expressed as mean \pm SD } \\
*: statistically significant in comparison to the control group $(\mathbf{P}<\mathbf{0 . 0 5})$. \\
\#: statistically significant in comparison to the group Q10 $(\mathbf{P}<\mathbf{0 . 0 5})$. \\
\$: statistically significant in comparison to the group ND $(\mathbf{P}<\mathbf{0 . 0 5})$.
\end{tabular}

Detection Of TGF B1 By ELISA

In the present study, analysis of TGF $\beta 1$ pro-fibrosis protein marker in serum by ELISA revealed a significant raise in the ND group in comparison to the control. While, a significant decrease in the level of TGF $\beta 1$ was recorded in the treated group in comparison to the ND group. (Table 4)

\section{Histopathological Examination}

In the present study, histological examination of the heart tissue sections of group I (control group) and group II (Q10 group) showed normal histological structure. Cross section of cardiac muscle section showed bundles of acidophilic muscle fibers with central located nuclei. The Masson's trichrome tissue section showed no fibrous connective tissue proliferation in-between muscle bundles and perivascular fig. 2 (Group I \& II b). TUNEL assay showed no immunoreactivity grade 0 fig. 2 (Group I \&II c).
Heart tissue section of group III (ND group) showed many necrotic muscle fibers that were seen in fig. 2 (Group III a).Fibrous connective tissue proliferation was detected by Masson's trichrome stain inbetween muscle bundles and perivascular which appeared as interstitial intermyocellular fibrosis in fig. 2 (Group III b). TUNEL assay showed immunopositivity in up to half cells grade 3 (fig.2 (Group III c)). Myocytes nuclei showed an intense, wide, positive reaction.

Group IV (treated group) showed mild intra-myocardial oedema with no necrosis of myocytes fig.2 (Group IV a). The fibrous connective tissue appeared very delicate with Masson's trichrome in comparison with group III fig. 2 (Group IV b). TUNEL assay showed mild immunopositivity in scattered cells grade 1 fig.2 (Group IV c). 


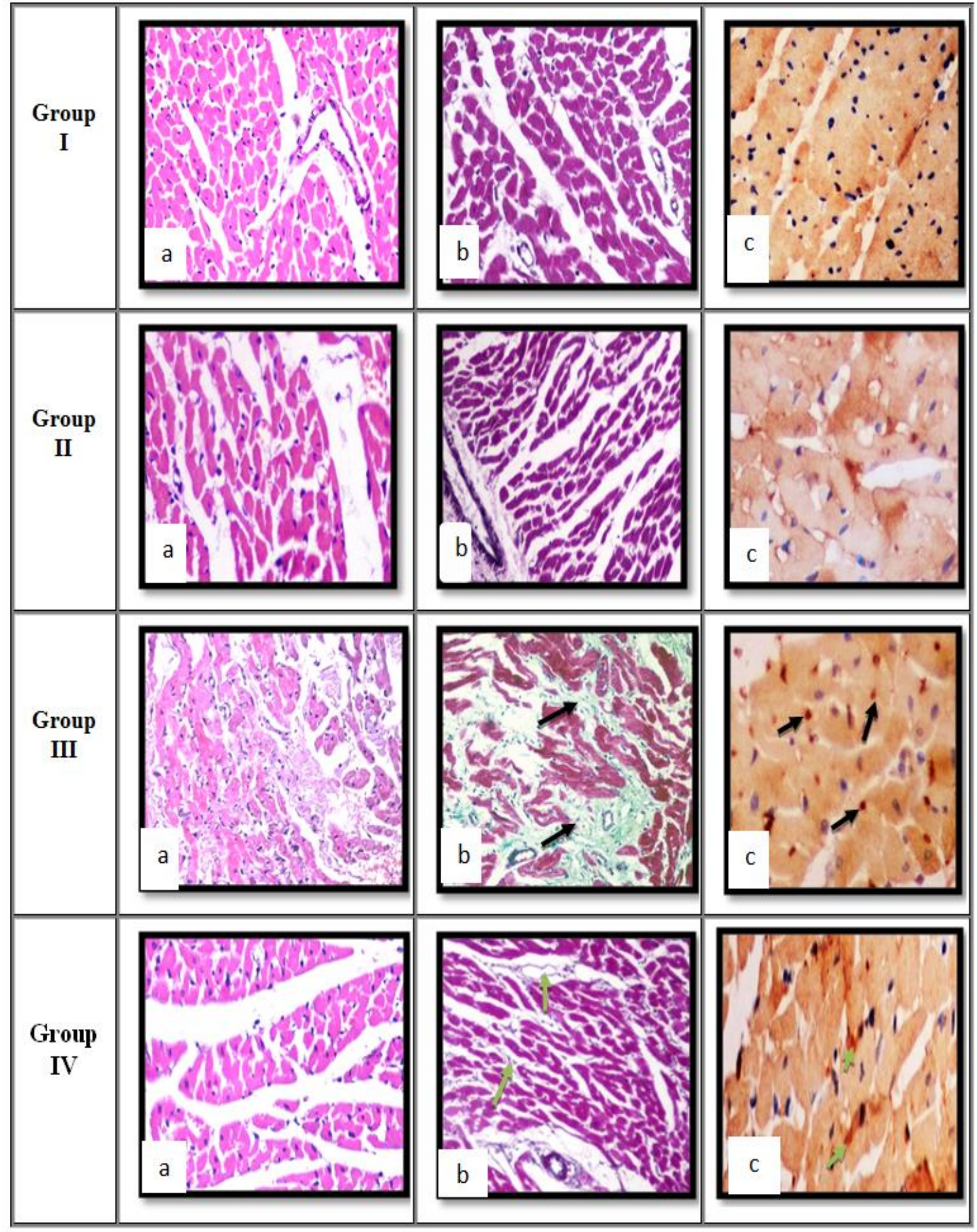

Figure (2): Photomicrograph of cardiac muscle section: Group I \& II (a) showing normal histological structure $(\mathrm{H} \& \mathrm{E})$ (b) showing no fibrous tissue proliferation (Masson's trichrome) (c) TUNEL assay showing no immunoreactivity grade 0. Group III (a) showing many necrotic muscle fibers (H\&E) (b) showing interstitial inter-myocellular fibrosis (Masson's trichrome) arrow (c) TUNEL assay showing immunopositivity in up to half cells grade 3 arrow. Group IV (a) showing mild intra-myocardial oedema (H\&E) (b) showing very delicate inter-myocellular fibrosis (Masson's trichrome) arrow (c) TUNEL assay showing mild immunopositivity in scattered cells grade 1 arrow. (a \& b X100) (c X400) 


\section{DISCUSSION}

Increasing different types of steroid products, administered in different forms with different combinations, leads to difficult interpretation of pathological findings and obscured evidence of relation between the use of doping and death to the forensic experts. Moreover, there are no pathological findings in humans specific for AASs (Hausmann, 2005). Consequently, the present study aimed to evaluate the role of Q10 in prevention of cardiotoxicity induced by nandrolone decanoate.

In this study, ND induced a significant reduction in the mitochondrial enzyme activity SDH in the cardiac tissue and a significant raise in the diagnostic marker of cardiac damage CK-MB in serum in comparison to the control rats. Creatine kinase-MB (CK-MB) is a greater and particular marker, considered as an indicator of myocardial necrosis (Ulla et al., 2017). Alterations in the levels of cardiac enzymes and cardiac markers have been reported in myocardial infarction (Miltonprabu and Thangapandiyan, 2015).

As the calcium $(\mathrm{Ca} 2+)$ is considered a minor messenger to maintain the mitochondrial functions, $\mathrm{Ca} 2+$ has a vital duty in the regulation of many cellular processes and signaling mechanisms resulted from outer or inner stimuli of mitochondria (Berridge et al., 2000). In this study, the result showed a significant raise in the $\mathrm{Ca} 2+$ level of cardiac mitochondria in ND group as compared to the control. This may result in a disorder of the proton gradient across the mitochondrial membrane, and thus reducing synthesis of the ATP in cardiomyocytes (Narayanan et al., 1991). It has been revealed that the increased concentrations of intracellular calcium resulted in impairment of the mitochondrial membranes permeability that led to the release of pro-apoptotic factors, hence induction of apoptosis (Fanton et al., 2009).

According to western blot analysis, our result revealed that ND induced significant reduction in survival (antiapoptotic) proteins for example p$\mathrm{PI} 3 \mathrm{~K}$, p-Akt, and Bcl-2 and significant increase of pro-apoptosis protein Bax. Chaves et al., 2006 have reported that the abuse of anabolic androgenic steroids (AAS) induced impairment in the antioxidant enzymes. Upregulation in accumulation of free radical in the cardiac mitochondria leads to disturbance in the energy of cardiomyocytes and decrease survival proteins and upregulates pro-apoptosis proteins resulting in a series of events including mitochondrial membrane instability, stimulation of caspase- 3 and caspase-9 and liberate of cytochrome c leading to cardiomyocyte apoptosis (Chahine et al., 2014; Liao et al., 2015).

The balance between the members of pro-apoptotic and anti-apoptotic family proteins predicts either the cell will stay alive or undergo apoptosis. Apoptosis is considered an important factor in the pathogenesis of different heart diseases (Miltonprabu and Thangapandiyan, 2015).

In the present study, real-time qRTPCR analysis showed a significant increase in the levels of fibrosis protein MMP-2 and MMP-9 gene expression in the heart tissue, and also ELISA assay in our study showed a significant increase in the profibrosis protein TGF b1 serum level. Damaged cardiomyocytes produce elevated levels of TGF b1 which attached to the cell surface TGF $b$ receptor and finally 
modifies MMP-2 and MMP-9 gene expression which leads to cardiac fibrosis (Chang et al., 2014; Lai et al., 2015). MMP-2 is considered a lineal arbitrator of systolic dysfunction and ventricular remodeling (Bergman et al., 2007). Moreover, Linthout et al., (2008) have demonstrated that the cardiac fibrosis is related to dysregulation in extracellular matrix degradation. The extent and direction of cardiovascular remodeling are evaluated by the role of MMPs in the extracellular matrix (Janssens and Lijnen, 2006). Previous researches have revealed that disturbance in the extracellular matrix (ECM) degradation by MMPs, especially the MMP-2, resulted in cardiac dysfunctions (Ahmed et al., 2006; Marqueti et al., 2012).

These results were reinforced by histological examination. The result revealed left ventricular hypertrophy as well as increased heart connective tissue content in the animals exposed to ND. Similarly, previous studies have shown that nandrolone abuse induced increase of left ventricular thickness (Frati et al., 2015; Montisci et al., 2012), and connective tissue content (Franquni et al., 2013). Cardiac hypertrophy is considered an indicator of progressive heart disease that results in heart failure which is accompanied by a disturbance in intracellular calcium level. Hence, heart failure is associated with cardiac hypertrophy (Hannan et al., 2003).

Q10 is an effective antioxidant and play an important role in adenosine triphosphate production in mitochondria (Tsuneki et al., 2007). It has been reported that Q10 can save endothelial cells from oxidative strain (Tsuneki et al., 2013). Cardiac dysfunctions for example cardiomyopathy, changes in structure and number of the mitochondria can affect the levels of Q10 (Bentinger et al., 2010).

In this study, evident protection of cardiac tissue by Q10 have been revealed against heart injury caused by ND to a significant increase in the heart mitochondrial enzyme SDH and a significant reduction in serum cardiac marker CK-MB in Q10 treated group as compared to ND toxic group. Ulla et al., (2017) support our finding; they also revealed that Q10 can decrease CK-MB activity. Consequently, treatment with Q10 showed a significant decrease in the cardiac mitochondrial $\mathrm{Ca} 2+$ level. The antioxidant membrane stabilizing actions of Q10 inhibits the seepage of cardiac markers from the cardiac tissues to blood, maintains myocardial calcium ion channels and inhibits mitochondrial deformity that may offer a way of mitochondrial preservation and decrease the cardiac tissue damage (Yeung et al., 2010).

Pretreatment with Q10 against ND can successfully activate p-PI3K, pAkt, and Bcl-2 survival proteins and prevent apoptosis protein Bax to overturn ND induced cardiac damages. Our result is in agreement with previous studies that proved treatment with Q10 can enhance survival protein expression to maintain cell life by performing as useful antioxidant and also downregulate proapoptotic proteins, hence, inhibit apoptosis (Chen et al., 2011; Zhang et al., 2015). Coenzyme Q10 is most likely an essential antioxidant in cardiomyocytes and afford an effective protection in opposition to ND-produced oxidative injury and cardiomyopathy to verify its antiapoptotic action (Conklin, 2005).

Moreover, Q10 significantly 
decreased MMP-2 and MMP-9 gene expression levels and profibrosis protein $\mathrm{TGFb} 1$ when compared toND intoxicated rats. Hence, Q10 prevents ND induced fibrosis in the cardiac tissue. This result is in accordance with Ulla et al., 2017 who proved the antifibrotic action of Q10 in heart and kidney.

The histopathological findings also supported our results that Q10 could protect the heart against ND-induced cardiac hypertrophy and apoptosis. Histological findings of the treated group showed no necrosis, fibrosis, and apoptosis. Thus, Q10 protected the cardiac tissue against ND induced cardiac damage.

\section{CONCLUSION}

The present study showed that the coenzyme Q10 treatment had significant cardioprotective effect against nandrolon decanoate administered rats. The antioxidant action of coenzyme Q10 could prevent fibrosis, apoptosis and maintain healthy cardiac tissue of ND treated rats for 4 weeks.

\section{FUNDING}

No funds have been received for this study.

\section{CONFLICT OF INTEREST}

There is no conflict of interest between authors.

\section{REFERENCES}

Ahlgrim, C. and Guglin, M. (2009):

Anabolics and cardiomyopathy in a bodybuilder: case report and literature review. Journal of Cardiac Failure, 15:496-500.

Bentinger, M.; Tekle, M. and Dallner, G. (2010): Coenzyme QBiosynthesis and functions. Biochemical and Biophysical
Researcch Communication, 396:7479.

Bergman, M.R.; Teerlink, J.R.; Mahimkar, R.; Li L, Zhu, B.Q.; Nguyen, A.; Dahi, S.; Karliner, J.S. and Lovett, D.H. (2007): Cardiac matrix metalloproteinase-2 expression independently induces marked ventricular remodeling and systolic dysfunction. American Journal of Physiology, 292:H1847H1860.

Berridge, M.J.; Lipp, P. and Bootman, M.D. (2000): The versatility and universality of calcium signaling. Nature Reviews Molecular Cell Biology, 1:11-21.

Cadenas, E. and Davies, K.J. (2000): Mitochondrial free radical generation, oxidative stress, and aging. Free Radical Biology \& Medicine, 29:222-230.

Cassileth, B.R.; Yeung, K.S. and Gubili, J. (2010): Herb-drug interactions in oncology. 2nd ed. People`s Medical Publishing House, PMPH-USA, 185-188.

Chahine, N.; Makhlouf, H.; Duca, L.; Martiny, L. and Chahine, $\mathbf{R}$. (2014): Cardioprotective effect of saffron extracts against acute doxorubicin toxicity in isolated rabbit hearts submitted to ischemiareperfusion injury. Zeitschrift Fur Naturforschung C, 69:459-470.

Chan, Y.H. (2003): Biostatistics102: Quantitative Data - Parametric \& Non-parametric Tests. Singapore Medical Journal, 44(8):391-396.

Chang, H.C.; Chiu, Y.W.; Lin, Y.M.; Chen, R.J.; Lin, J.A.; Tsai, F.J.; Tsai, C.H.; Kuo, Y.C.; Liu, J.Y. and Huang, C.Y. (2014): Herbal supplement attenuation of cardiac fibrosis in rats with $\mathrm{CCl}(4)$-induced liver cirrhosis. Chinese Journal of 
Physiology, 57:41-47.

Chaves, E.A.; Pereira-Junior, P.P.; Fortunato, R.S.; Masudaa, M.O.; Campos, D.; Carvalho, A.C.; Pires de Carvalho, D.; Oliveira, M.F. and Nascimento, J.H.M. (2006): Nandrolone decanoate impairs exercise-induced cardioprotection: Role of antioxidant enzymes. Journal of Steroid Biochemistry \& Molecular Biology, 99:223-230.

Chen, C.C.; Liou, S.W.; Chen, C.C.; Chen, W.C.; Hu, F.R.; Wang, I.J. and Lin, S.J. (2011): Coenzyme Q10 reduces ethanol-induced apoptosis in corneal fibroblasts. PLoS One, 6:e19111.

Chen, P.; Hou, C.W.; Shibu, M.A.; Day, C.H.; Pai, P.; Liu, Z.R.; Lin, T.Y.; Viswanadha, V.P.; Kuo, C.H. and Huang, C.Y. (2017): Protective Effect of Co-Enzyme Q10 On Doxorubicin-Induced Cardiomyopathy of Rat Hearts. Environmental Toxicology, 32(2):679-689.

Conklin, K.A. (2005): Coenzyme q10 for prevention of anthracyclineinduced cardiotoxicity. Integrative Cancer Therapies, 4:110-130.

Duberley, K.E.; Heales, S.J.; Abramov, A.Y.; Chalasani, A.; Land, J.M.; Rahman, S. and Hargreaves. I.P. (2014): Effect of Coenzyme Q10 supplementation on mitochondrial electron transport chain activity and mitochondrial oxidative stress in Coenzyme Q10 deficient human neuronal cells. International Journal of Biochemical Cell Biology, 50:6063.

El-Sayed, S.M.; Mansour, A.M. and Abdul-Hameed. M.S. (2016): Thymol and carvacrol prevent doxorubicin-induced cardiotoxicity by abrogation of oxidative stress, inflammation, and apoptosis in rats. Journal of Biochemical \& Molecular Toxicology, 30:37-44.

Fanton, L.; Belhani, D.; Vaillant, F.; Tabib, A.; Gomez, L.; Descotes, J.; Dehina, L.; Bui-Xuan, B.; Malicier, D. and Timour, $\mathbf{Q}$. (2009): Heart lesions associated with anabolic steroid abuse: comparison of postmortem findings in athletes and norethandroloneinduced lesions in rabbits. Experimental Toxicology \& Pathology, 61:317-323.

Figueredo, V.M. (2011): Chemical cardiomyopathies: the negative effects of medications and nonprescribed drugs on the heart. American Journal of Medicine, 124:480-488.

Fineschi, V.; Di Paolo, M.; Neri, M.; Bello, $\quad$ S.; D'Errico, S.; Dinucci, $\quad$ D.; Parente, R.; Pomara, C.; Rabozzi, R.; Riezzo, I.; Turillazzi E. (2011): Anabolic Steroid and Exercise-Induced CardioDepressant Cytokines and Myocardial Receptor Expression in CD1 Mice. Current Pharmaceutical \& Biotechnology, 12:275-284.

Franquni, J.V.; do Nascimento, A.M.; de Lima, E.M.; Brasil, G.A.; Heringer, O.A.; Cassaro, K.O.; da Cunha, T.V.; Musso, C.; Silva Santos, M.C.; Kalil, I.C.; Endringer, D.C.; Boëchat, G.A.; Bissoli, N.S. and de Andrade, T.U. (2013): Nandrolone decanoate determines cardiac remodeling and injury by an imbalance in cardiac inflammatory cytokines and ACE activity, blunting of the BezoldJarisch reflex, resulting in the development of hypertension. Steroids, 78(3):379-85. 
Frati, P.; Busardo, F.P.; Cipolloni, L.; Dominicis, E.D. and Fineschi, V. (2015): Anabolic androgenic steroids (AAS) related deaths: autoptic, histopathologycal and toxicological findings. Current Neuropharmacology, 13(1):146-59.

Hausmann, R. (2005): Long-Term Effects of Anabolic-AndrogenicSteroid Abuse. Forensic Pathology Reviews, 2: 273-289.

Hechtman, L. (2014): Clinical naturopathic medicine. Part 2: naturopathic treatments, chapter 5: nutrition medicine. Luisa Cecotti, Churchill livingstone, Elsevier Australia, 50-71.

Janssens, S. and Lijnen, H.R. (2006): What has been learned about the cardiovascular effects of matrix mettaloproteinases from mouse models? Cardiovascular Research, 69:585-594.

Kochakian, C.D. (2012): Anabolicandrogenic steroids. Historical review of anabolic-androgenic steroids. Springer-Verlag, Berlin Heidelberg, New York, 2-5.

Lai, C.H.; Han, C.K.; Shibu, M.A.; Pai, P.Y.; Ho, T.J.; Day, C.H.; Tsai, F.J.; Tsai, C.H. and Yao, C.H.; Huang, C.Y. (2015): Lumbrokinase from earthworm extract ameliorates second-hand smoke-induced cardiac fibrosis. Environmental Toxicology, 30:1216-1225.

Liao, H.E.; Shibu, M.A.; Kuo, W.W.; Pai, P.Y.; Ho, T.J.; Kuo, C.H.; Lin, J.Y. and Wen, S.Y. (2015): Viswanadha VP, Huang CY. Deep sea minerals prolong life span of streptozotocin-induced diabetic rats by compensatory augmentation of the IGF-I-survival signaling and inhibition of apoptosis. Environmental Toxicology,
31(7):769-81.

Linthout, V.S.; Seeland, U.; Riad, A.; Eckhardt, O.; Hohl, M.; Dhayat, N.; Richter, U.; Fischer, J.W.; Böhm, M.; Pauschinger, M.; Schultheiss, H.P. and Tschöpe, C. (2008): Reduced MMP-2 activity contributes to cardiac fibrosis in experimental diabetic cardiomyopathy. Basic Research of Cardiology, 103:319-327.

Luijkx, T.; Velthuis, B.K.; Backx, F.J.G.; Buckens, C.F.M.; Prakken, N.H.J.; Rienks, R.; Mali, W. and Cramer, M.J. (2013): Anabolic androgenic steroid use is associated with ventricular dysfunction on cardiac MRI in strength trained athletes. International Journal of Cardiology, 167:664-668.

Mark, P.B.; Watkins, S. and Dargie, H.J. (2005): Cardiomyopathy induced by performance enhancing drugs in a competitive bodybuilder. Heart, 91(7):888.

Marqueti, R.C.; Micocci, K.C.; Leite, R.D. and Selistre-de-Araujo, H.S. (2012): Nandrolone Inhibits MMP2 in the Left Ventricle of Rats. Int $\mathbf{J}$ Sports Med.;33:181-185.

Miltonprabu, S. and Thangapandiyan, S. (2015): Epigallocatechin gallate potentially attenuates Fluoride induced oxidative stress mediated cardiotoxicity and dyslipidemia in rats. Journal of Trace Elements of Medicine \& Biology, 29:321-335.

Montisci, M.; El Mazloum, R.; Cecchetto, G.; Terranova, C.; Ferrara, S.D.; Thiene, G. and Basso, C. (2012): Anabolic androgenic steroids abuse and cardiac death in athletes: morphological and toxicological findings in four fatal cases. 
Forensic Science International, 217(1-3):e13-18.

Montisci, M.; El Mazloum, R.; Cecchetto, G.; Terranova, C.; Ferrara, S.D.; Thiene, G. and Basso, C. (2012): Anabolic androgenic steroids abuse and cardiac death in athletes: morphological and toxicological findings in four fatal cases. Forensic Science International, 217:e13-e18.

Narayanan, N.; Su, N. and Bedard, P. (1991): Inhibitory and stimulatory effects of Fluoride on the calcium pump of cardiac sarcoplasmic reticulum. Biochimica et Biophysica Acta, 1070:83-91.

Niklowitz, P.; Sonnenschein, A.; Janetzky, B.; Andler, W. and Menke, T. (2007): Enrichment of coenzyme Q10 in plasma and blood cells: Defense against oxidative damage. International Journal of Biological Science, 3:257-262.

Nikolic, T.; Zivkovic, V.; Jevdjevic, M.; Djuric, M.; Srejovic, I.; Djuric, D.; Jeremic, N.; Djuric, D.; Bolevich, S. and Jakovljevic, V. (2015): The effects of chronic administration of nandrolone decanoate on redox status in exercised rats. Molecular \& Cellular Biochemistry, 411(12):95-105.

Rocha, F.L.; Carmo, E.C.; Roque, F.R.; Hashimoto, N.Y.; Rossini, L.V.; Frimm, C.; Aneas, I.; Neagro, C.E.; Krieger, J.E. and Oliveira, E.M. (2007): Anabolic steroids induce cardiac reninangiotensin system and impair the beneficial effects of aerobic training in rats. American Journal of Physiology Heart \& Circulatory Physiology, 293(6):H3575-H3583.

Sretenovic, J.; Zivkovic, V.; Srejovic,
I. and Milosavljevic, Z. (2016): The effects of high doses of nandrolone decanoate on cardiac muscle tissue. Serbian Journal of Experimental \& Clinical Research, 4:303-308.

Suchalatha, S.; Srinivasan, P. and Devi, C.S. (2007): Effect of T. chebula on mitochondrial alterations in experimental myocardial injury. ChemicoBiological Interactions, 169:145153.

Takasawa, M.; Hayakawa, M.; Sugiyama, S.; Hattori, K.; Ito, T. and Ozawa, T. (1993): Ageassociated damage in mitochondrial function in rat hearts. Experimenal Gerontology, 28:269-280.

Tsuneki, H.; Sekizaki, N.; Suzuki, T.; Kobayashi, S.; Wada, T.; Okamoto, T.; Kimura, I. and Sasaoka, T. (2007): Coenzyme Q10 prevents high glucose-induced oxidative stress in human umbilical vein endothelial cells. European Journal Pharmacology, 566:1-10.

Tsuneki, H.; Tokai, E.; Suzuki, T.; Seki, T.; Okubo, K.; Wada, T.; Okamoto, T.; Koya, S.; Kimura, I. and Sasaoka, T. (2013): Protective effects of coenzyme Q10 against angiotensin II-induced oxidative stress in human umbilical vein endothelial cells. European Journal Pharmacology, 701:218227.

Ulla, A.; Mohamed, M.K.; Sikder, B.; Rahman, A.; Sumi, F.A.; Hossain, M.; Reza, H.M.; Rahman, G.M.S. and Alam, M.A. (2017): Coenzyme Q10 prevents oxidative stress and fibrosis in isoprenaline induced cardiac remodeling in aged rats. BMC Pharmacology \& Toxicology, 18(1):29. 
Vasilakia, F.; Tsitsimpikoub, C.; Tsarouhasc, K.; Germanakisd. I.; Tzardie, M.; Kavvalakisa, M.; Ozcaglif, E.; Kouretasg, D. and Tsatsakis, A.M. (2016): Cardiotoxicity in rabbits after longterm nandrolone decanoate administration. Toxicology Letters, 241:143-151.

Wassef, M.A.E.; Tork, O.M.; Rashed, L.A.; Ibrahim, W.; Morsi, H.and Rabie, D.M.M. (2017): Mitochondrial Dysfunction in Diabetic Cardiomyopathy: Effect of Mesenchymal Stem Cell with PPAR- $\gamma$ Agonist or Exendin-4. Experimental \& Clinical Endocrinology \& Diabetes. doi: 10.1055/s-0043-106859.

Wysoczanski, M.; Rachko, M. and Bergmann, S.R. (2008): Acute myocardial infarction in a young man using anabolic steroids. Angiology, 59:376-378.

Yeung, C.K.; Billings, F.T.; Claessens, A.J.; Roshanravan, B.; Linke, L.; Sundell, M.B.; Ahmad, S.; Shao, B.; Shen, D.D. and Ikizler, T.A. (2015): Coenzyme Q10 dose-escalation study in hemodialysis patients: Safety, tolerability, and effect on oxidative stress. BMC Nephrology, 16:183.

Zhang, D.; Yan, B.; Yu, S.; Zhang,C.; Wang, B.; Wang, Y.; Wang, J.; Yuan, Z.; Zhang, L. and Pan, J. (2015): Coenzyme Q10 inhibits the aging of mesenchymal stem cells induced by D-galactose through Akt/mTOR signaling. Oxidative Medicine \& Cellular Longevity, 867293. doi: 10.1155/2015/867293. 


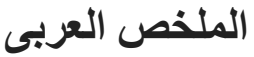

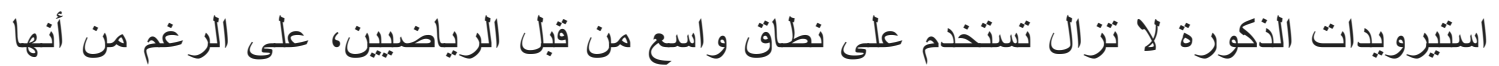

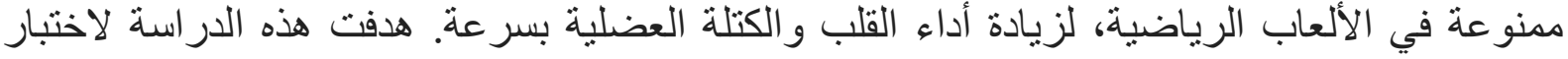

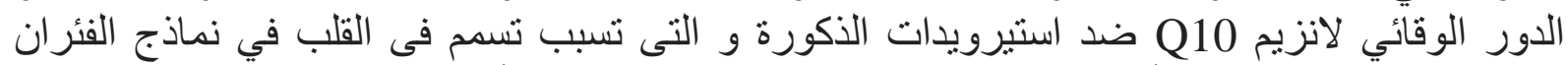

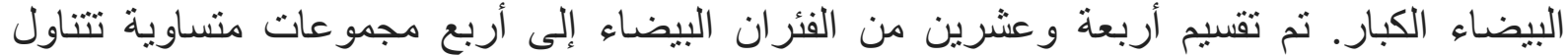

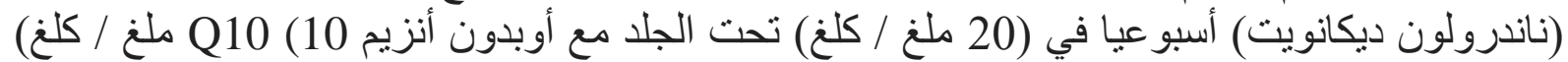

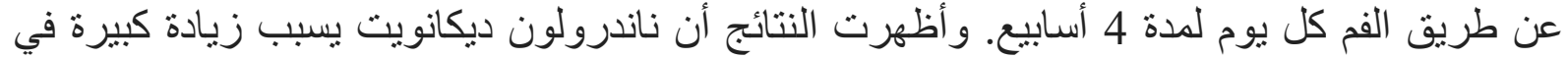

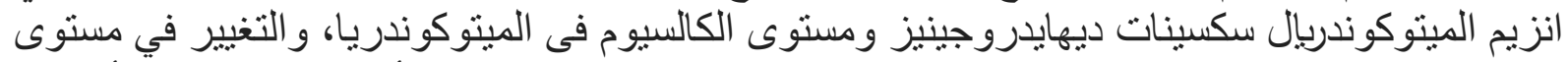

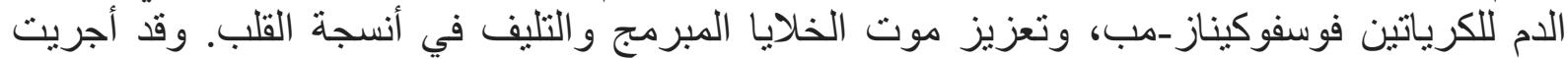
دراسة هستوباثولوجية لأنسجة القلب. العلاج مع Q10 يمكن أن يخفق من الآثار السامة الناجمة عن الناتئ

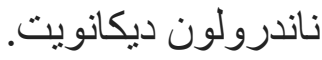

